\title{
Desenvolvimento de objeto de aprendizagem para o estudo interativo de Bioquímica Celular
}

\section{Development of learning objects for the study of interactive Cellular Biochemistry}

Ítalo Esposti Poly da Silva ${ }^{1}$

Mariana de Souza Silva ${ }^{1}$

Lucas Silva Azevedo ${ }^{1}$

Fabiano Oliveira Prado

Wendel Mattos Pompilho ${ }^{3}$

\section{Resumo}

Este trabalho descreve o desenvolvimento de um objeto de aprendizagem aplicado no ensino de bioquímica celular para alunos do Ensino Médio. Trata-se de um software composto por um banco de dados com perguntas versando sobre o tema anteriormente citado.

Pavavras-chave: Bioquímica Celular, Ensino Médio, Objetos de Aprendizagem.

\section{Abstract}

This paper describes the development of a learning object used in the teaching of cellular biochemistry for High Senior school students. This is a software system comprising a database dealing with questions on the subject previously mentioned.

Keywords: Cellular Biochemistry, High School, Learning Object. 


\section{INTRODUÇÁO}

Durante o Ensino Médio os estudantes mantêm contato com diversos conceitos de Bioquímica Celular, tais como: respiração e replicação celular, síntese de proteínas, fotossíntese etc. (BRASIL, 2009). Tais temas, por serem complexos e abstratos nem sempre são bem compreendidos pelos alunos. Na tentativa de reverter essa situação, atualmente, é possível desenvolver práticas pedagógicas utilizando recursos digitais dinâmicos e interativos, os quais são utilizados como material didático de apoio ao conteúdo presente nos livros texto (KRASILCHIK, 2004; LUZ, 2004).

Recursos, digitais ou não digitais, que possam ajudar no processo de ensino e ser reutilizados em diversos contextos são denominados de Objetos de Aprendizagem (OA) (SANTOS, et al., 2007).

Os OAs apresentam características fundamentais para o processo de ensino/aprendizagem. Dentre elas destacamse, um papel mais ativo, dos alunos, com possibilidade de alteraçóes no ritmo da aprendizagem, bem como capacidade de adaptação às necessidades, competências, habilidades, formação, interesses e estilos cognitivos de cada um. Outro ponto positivo, para o uso dos OAs, é possibilidade de serem acessados de qualquer lugar e a qualquer tempo (KRATZ, et al., 2007).

Este trabalho descreve o desenvolvimento de um Objeto de Aprendizagem usando recursos multimídia interativos para a compreensão do tema Bioquímica Celular. O software desenvolvido é um jogo, o qual foi denominado Corrida Metabólica, e possui um banco de questóes direcionadas aos alunos de Ensino Médio.

\section{METODOLOGIA}

Foi desenvolvido um software em linguagem Delphi (Object Pascal). O programa armazena questóes em um banco de dados (Firebird ${ }^{\oplus}$ ) e faz buscas aleatórias, quando solicitado. Cada questão é constituída por cinco afirmativas, as quais apenas uma é verdadeira. As questôes abordam o conteúdo de Bioquímica Celular referente à matriz curricular do Ensino Médio.

Foi adicionado um método chamado Sorte ou Revés que faz buscas, aleatórias, de tarefas no banco de dados.

A interatividade do software dá-se por meio de três arquivos de áudio, um para abertura e apresentação do jogo e os demais para o acerto ou erro das respostas.

Utilizando o software Adobe Photoshop $\mathrm{CS}^{\circ}$ desenhouse um tabuleiro para a movimentação das peças do jogo.

\section{RESULTADOS E DISCUSSÃO}

É inegável a importância das aulas expositivas no processo de ensino/aprendizagem, porém a predominância desta abordagem torna as aulas cansativas e pouco atrativas. A mudança na metodologia de um ensino puramente teórico para uma metodologia que favoreça a participaçáo ativa dos alunos pode contribuir em envolvimento e entusiasmo, despertando a criatividade e interesse, tornando o aprendizado dinâmico e atrativo aos alunos. Neste contexto, foi desenvolvido o software "Corrida Metabólica".

No momento em que o software é acessado, um arquivo de áudio dá boas vindas aos usuários e algumas informações sobre o jogo. Em seguida, os ícones de navegação são liberados. Na Figura 1 é possível observar, em sua parte superior, os botôes do menu principal, os quais são, Sortear (sortear pergunta), Gabarito e Sorte ou revés.

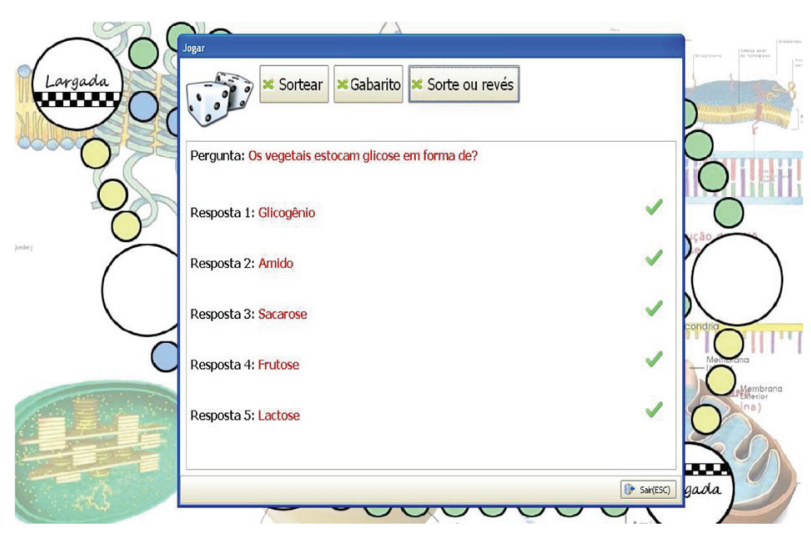

Figura 1 Layout do Jogo.

O jogo tem início ao clicar no botâo "Sortear", desta forma o programa fará uma busca aleatória de uma questão em seu banco de dados. Respondendo corretamente o usuário poderá locomover seu pino no tabuleiro do jogo (Figura 2). A quantidade de casas que deverá locomover é data em função do acerto da questáo. Cada questão tem uma pontuação diferente, variando com o nível de dificuldade da mesma.

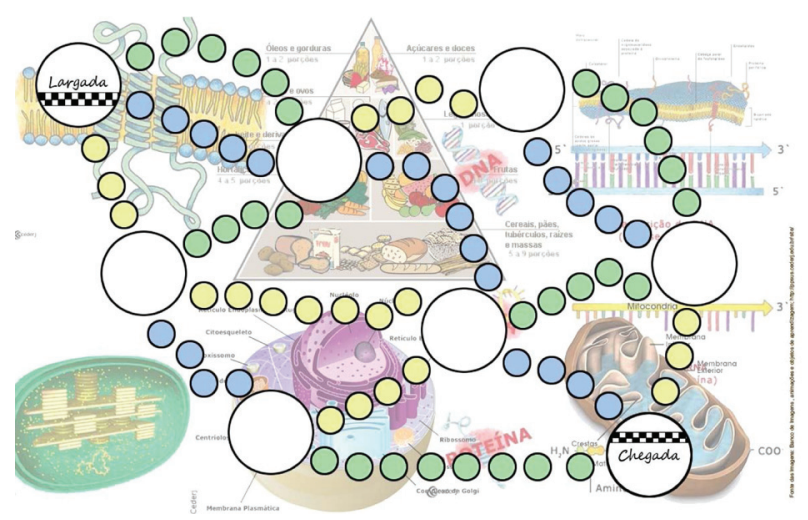

Figura 1 Layout do Tabuleiro. 
No tabuleiro de jogo existem três possibilidades de caminhos, as quais estão representadas por círculos pequenos nas cores verde, azul e amarela. Observe na figura 2 que existem caminhos curtos e caminhos longos. Toda vez que o jogador chegar a um dos círculos maiores (branco) ele deverá clicar no botáo sorte ou revés, o qual vai determinar o caminho a seguir. $\mathrm{O}$ vencedor do jogo é o primeiro que cruzar a linha de chegada.

É importante destacar que a criatividade é fundamental para o bom uso de um OA. Neste sentido, o OA "Corrida Metabólica" pode ser utilizado pelos professores da forma mais adequada aos alunos e à escola, podendo ser um jogo de pergunta e respostas ou um jogo de tabuleiro. $\mathrm{Na}$ opção jogo de perguntas e respostas é possível utilizar uma projeção do tipo multimídia em uma das paredes da sala. Cumpre ressaltar, a importância de uma boa interação entre os alunos de forma a estabelecer uma capacidade de cooperação, bem como estimular um papel ativo na compreensão dos processos metabólicos proposto por este $\mathrm{OA}$.

No processo de desenvolvimento do OA "Corrida Metabólica" foi priorizada a necessidade de reutilização. Destacando sua capacidade de adaptação aos anseios de educadores e educandos. O software em questão possui um banco de dados completamente reprogramável, sendo possível ampliar o número de questóes ou mesmo apagar as informaçôes nele contido. Desta forma, é possível que professores de outras áreas do conhecimento possam utilizar o software em sua disciplina, para isso basta apenas modificar as questóes do banco de dados.

\section{CONSIDERAÇÓES FINAIS}

Este OA foi concebido com intuito de facilitar o processo de ensino/aprendizagem de alunos do Ensino Médio por meio de um jogo interativo que privilegia a cooperação entre eles. Com o propósito de validação estatística, atualmente, o software "Corrida Metabólica" encontra-se em fase de apresentação aos alunos de Ensino Médio da rede pública na Região Noroeste Fluminense.

Futuramente, o software será depositado no Banco Internacional de Objetos Educacionais (http://objetoseducacionais2.mec.gov.br/).

\section{REFERÊNCIAS BIBLIOGRÁFICAS}

1. BRASIL (1999). Parâmetros Curriculares Nacionais: Ensino Médio: ciências da natureza, matemática e suas tecnologias. Brasília: MEC/Secretaria de Educação Média Tecnológica.

2. KRASILCHIK, M. (2004). Prática de ensino de Biologia. 4. ed. São Paulo: EPU/EDUSP.

3. KRATZ, R. A.; PINTO, S. C. C. S.; SCOPEL, M.; BARBOSA, J. (2007). Fábrica de Adequação de Objetos de Aprendizagem. Revista Brasileira de Informática na Educação. v. 15, n. 3, p. 25-38.

4. LUZ, M. R. M. P. da (2004). Instrumentaçáo ao Ensino de Bioquímica e Biologia Celular. V.1, Rio de Janeiro, Fundação CECIERJ.

5. SANTOS, L. M. A.; FLÔRES, M. L. P.; TAROUCO, L. M. R. (2007). Objetos de aprendizagem: teoria instrutiva apoiada por computador. Revista Novas Tecnologias na Educaçáo. Porto Alegre, v. 6, n. 2, p. 1-10.

Endereço para Correspondência:

Wendel Mattos Pompilho - wendelpompilho@yahoo.com.br UNIG Campus V

Av. Cel. Macário, no 2009 - Retiro do Muriaé

Itaperuna - RJ

CEP: 28330-000 